\title{
Atmospheric pollutants in a changing environment: key issues in reactivity and monitoring, global warming, and health
}

\author{
Elena Jiménez • Francisco J. Tapiador • \\ Francisco J. Sáez-Martínez
}

Received: 22 October 2014 / Accepted: 10 November 2014 / Published online: 29 November 2014

(C) Springer-Verlag Berlin Heidelberg 2014

Atmospheric pollutants change our environment in a variety of ways. Specifically, airborne pollution is known to harm forests, crops, wildlife, aquatic ecosystems, and freshwater. In addition to damaging the natural environment, air pollution also affects buildings and the cultural material heritage such as outdoor sculptures and carvings.

Direct effects of atmospheric pollutants on local and regional air quality and therefore on human health are a major concern. The European Environment Agency (EEA 2013) reported that despite the significant decrease of emissions over the past decades, the levels of air pollutants still frequently exceed the thresholds set by the European Union Air Quality Directives. In many parts of Europe, the levels of sulfur dioxide $\left(\mathrm{SO}_{2}\right)$, nitrogen oxides $\left(\mathrm{NO}_{x}\right)$, ammonia $\left(\mathrm{NH}_{3}\right)$, and non-methane volatile organic compounds (NMVOCs) are becoming a public health risk issue. The same applies to particulate matter (PM) levels. The World Health Organization has recently reported that black carbon (BC) may not be a major toxic component of fine PM, but it may operate as a universal carrier of a wide variety of toxic chemicals to

Responsible editor: Philippe Garrigues

E. Jiménez $(\bowtie)$

Department of Physical Chemistry, Faculty of Chemical Sciences and Technology, Avda. Camilo José Cela, s/n, 13071 Ciudad Real, Spain

e-mail: Elena.Jimenez@uclm.es

\section{F. J. Tapiador}

Faculty of Environmental Sciences and Biochemistry, Avda. Carlos III s/n, 45071 Toledo, Spain

e-mail: Francisco.Tapiador@uclm.es

\section{F. J. Sáez-Martínez}

Campus de Excelencia Internacional CYTEMA, Vicerrectorado de Investigación y Política Científica, Universidad de Castilla-La Mancha, Plaza de la Universidad, 2, 02071 Albacete, Spain e-mail: Francisco.Saez@uclm.es different parts of the body (Janssen et al. 2012). High levels of pollutants, especially tropospheric ozone $\left(\mathrm{O}_{3}\right)$, adversely affect human health by causing respiratory problems and vegetation and ecosystem damage (EPA). Ozone is formed from the atmospheric degradation of NMVOCs, such as alkanes, alkenes, and oxygenated compounds (aldehydes and esters), in the presence of $\mathrm{NO}_{x}$ and sunlight. Ground-level ozone is also a potent greenhouse gas $(\mathrm{GHG})$ that modifies the atmospheric radiative forcing and, thus, global temperatures. GHGs such as carbon dioxide $\left(\mathrm{CO}_{2}\right)$ and methane $\left(\mathrm{CH}_{4}\right)$ and, in a lesser extent, nitrous oxide $\left(\mathrm{N}_{2} \mathrm{O}\right)$ and fluorinated compounds are behind pressing global environmental problems such as the warming of Earth's atmosphere. Another climate forcer of combustion-related air pollution is $\mathrm{BC}$ aerosols (commonly referred to as "soot"), which directly absorb both the incoming and reflected sunlight and the infrared radiation, increasing the surface air temperature.

This Special Issue (SI) of Environmental Science and Pollution Research addresses some of those problems, with special emphasis on tropospheric reactivity, gas monitoring, and the potential impacts of air pollution on climate and people and biota. Drawing from selected contributions to the 2013 Energy and Environment Knowledge Week (E2KW International Congress, Toledo, Spain), the SI gathers novel and timely research on how atmospheric pollutants modify our environment, also highlighting the many links between energy Research Development and Demonstration (RD\&D) policies and GHG emissions.

\section{Air quality: gaseous pollutants and nanoparticles}

Unraveling the complex photochemical processes in the atmosphere is one of the key topics likely to bring new insight into the role of pollutants in the environment. For that reason, the knowledge of the atmospheric chemistry of emitted 
pollutants and the potential to form ground-level $\mathrm{O}_{3}$ are of great importance in the evaluation of their effects on air quality and climate change. Pollutants homogeneously react with the main tropospheric oxidants, especially with highly reactive radical species such as $\mathrm{OH}$ and $\mathrm{Cl}$. Therefore, it is not surprising that detailed analysis of free radical-molecule reaction kinetics and mechanisms of NMVOCs has been a subject of continuous interest in environmental studies. It is deemed that the chemical kinetic and mechanistic studies on potential high GWP HFC substitutes, like $\mathrm{CF}_{3} \mathrm{CH}=\mathrm{CH}_{2}$ (HFO-1243zf) (González et al. 2015), on hydrocarbons emissions from vehicle exhaust, like cycloalkanes (Ballesteros et al. 2015), and on primary and secondary pollutants, like alkyl esters (Ifang et al. 2015), can help to understand the key interplay between human/natural activity and air pollution phenomena induced by photochemical processes and therefore drive further advance in the field. While reaction initiated by $\mathrm{OH}$ radicals is the main degradation pathway (González et al. 2015; Ballesteros et al. 2015), chlorine chemistry can be a competitive process at dawn in the marine/coastal boundary layer (Ballesteros et al. 2015; Ifang et al. 2015). The comprehensive degradation mechanisms proposed by Ballesteros et al. (2015) and Ifang et al. (2015) can be included in chemical transport models. The subtle details involved in the description of these photochemical processes illustrate the complex relationships emerging from the joint considerations of just a few species and a single process. Thus, the atmospheric fate of NMVOCs depends on their atmospheric lifetimes and the reaction degradation products, mainly oxygenates and ultimately ozone in high $\mathrm{NO}_{x}$ environments. Further degradation of secondary pollutants - ketones and aldehydes - initiated by sunlight can be an important removal pathway in the atmosphere (Ballesteros et al. 2015; Ifang et al. 2015). However, this route represents a negligible contribution to the elimination process for their atmospheric precursors, HFO-1243zf (González et al. 2015), for methylcyclohexanes (Ballesteros et al. 2015) and alkyl esters (Ifang et al. 2015). González et al. (2015) confirm that the potential of HFO-1243zf to form ground-level ozone is low enough to rule it out as a substantial contributor to photochemical smog.

A major challenge in tropospheric chemistry is to accurately model the important and complex chemistry in solid (heterogeneous chemistry) or liquid particles (multi-phase chemistry) (Ravishankara 1997). Fossil fuel and biomass combustion are the main sources of atmospheric aerosols. Particularly, BC nanoparticles formed in the incomplete combustion of hydrocarbons in diesel engines are of great interest nowadays because they present a wide range of geophysical and environmental problems, ranging from local issues (e.g., pollution toxicity) to the global scale (e.g., climate change). In some cases, its environmental impact is even greater than gaseous pollutants. Indeed, as the effects of black carbon have become better understood in recent years, it is increasingly seen as an important target of environmental control. Therefore, laboratory kinetic measurements of uptake coefficients in such aerosols, as those presented in this SI for a diesel soot by Tapia et al. (2015), are extremely important.

Special attention is also drawn in this SI to the monitoring and dispersion modeling of atmospheric pollutants (Esbrí et al. 2015). This is a key issue for increasing our knowledge on the role of these gases on local and regional air quality. The dispersion model developed by Esbrí et al. (2015) is a very useful tool for assessing the risk of the mercury exposure to the local population close to a mercury cell chlor-alkali plant. The atmospheric $\mathrm{Hg}$ dispersion model demonstrates that the most Hg-polluted atmosphere in Spain is located around a mercury cell chlor-alkali plant close to the Ebro River basin. Currently, the $\mathrm{Hg}$ levels are above international thresholds for residential areas (Esbrí et al. 2015).

Another relevant aspect of air pollution is indoor air quality since indoor air is eventually mixed with outdoor air before passing through ventilation ducts (Da et al. 2015). Especially in food industries, experimental protocols for a better control of aerosol particle transport and deposition in the ventilation ducts are of great help (Da et al. 2015).

\section{Global warming and GHG emissions}

In addition to combustion of fossil fuels, biomass burning including forest fires and agricultural waste burning is one of the major sources of $\mathrm{GHG} \mathrm{CO}_{2}$ and thus deserve a special focus in terms of policymaking. The role of forest in carbon cycle and $\mathrm{H}_{2} \mathrm{O}$ budget is well known. For that reason, wildfires greatly modify $\mathrm{CO}_{2}$ and $\mathrm{H}_{2} \mathrm{O}$ fluxes. In this special issue, Dadi et al. (2015) evaluate the effect of wildfires in the $\mathrm{CO}_{2}$ and $\mathrm{H}_{2} \mathrm{O}$ flux exchange between a Mediterranean ecosystem (Spanish coniferous forest) and the atmosphere 2 years after the event. Dadi et al. (2015) concluded that post-wildfires are a carbon source while the water flux was less dramatically affected.

Precise measurements and modeling are also critical to provide further advance in reducing GHG emissions and to inform environmental policies. Notwithstanding that the reduction in GHG emission observed in Europe over the last two decades is a result of the economic restructuring that occurred in the Eastern Europe Area (EEA) in the 1990s (Balsalobre et al. 2015), the EU is making sustained progress towards achieving its emission reduction targets: Between 1990 and 2008, EEA countries collectively reduced greenhouse gas emissions by $7.5 \%$ and per capita emissions from 10.9 to 9.3 metric tonnes $\mathrm{CO}_{2}$ equivalent. The EU-27 has recently set an independent target to reduce greenhouse gas emissions by 2020 by at least $20 \%$ compared to the 1990 levels. On this direction, the characterization of the radiative properties of emerging solutions for industrial problems is a 
must. This is the case of the substitution of HFC-134a $\left(\mathrm{CF}_{3} \mathrm{CFH}_{2}\right)$ by $\mathrm{HFO}-1243 \mathrm{zf}$ in air-conditioning units. González et al. (2015) report that the contribution of HFO$1243 \mathrm{zf}$ to global warming is expected to be negligible compared with that of the potent greenhouse gas HFC-134a. Here and given the major role of fossil fuels on carbon emissions, careful characterization of soot from diesel engines (Tapia et al. 2015) is critical for a better understanding of the global radiative effects of these atmospheric aerosols and thus on the overall role of pollutants in the environment.

\section{Impacts on health}

Health is another key topic that merits specific attention. Thus, for instance, heavy metal emissions exert a direct effect on biota, having been widely recognized as a public health concern. Considerable progress has been made in Europe to reduce emissions and traditional careless exposure to heavy metals. As shown by Esbrí et al. (2015), even in developed areas, the levels of atmospheric $\mathrm{Hg}$ have been for too long consistently exceeding the thresholds set by the World Health Organization, as featured in series from 1900 to as far as 2000 in the Almadén Hg mining district (Tejero et al. 2015). Even though clinical studies have not been performed on the general population of this mining area, studies on exposed workers (García-Gómez et al. 2007) describe high Hg levels in blood and urine and detrimental effects on the central nervous and urinary systems. Here, case studies illustrate the importance of policy action: Improved controls on $\mathrm{Hg}$ cells used in industrial processes (e.g., in the chlor-alkali process) resulted in emissions reduced by $66 \%$ between 1990 and 2011 (EEA 2013). This example also highlights the importance of measurement protocols and cycle analyses, as significant differences between diurnal and nocturnal $\mathrm{Hg}$ concentrations are observed.

As already stated, particle organic compounds present on the $\mathrm{BC}$ nanoparticle surface may trigger oxidative or harmful degradation mechanisms. Characterization of the interfacial functional groups of the $\mathrm{BC}$ nanoparticles from diesel exhaust (Tapia et al. 2015) reveals the exceptional reducing properties of the investigated soot which may have potential toxicological effects. However, to better examine the effect of these aerosols on the human health, the use of a biological marker is required.

The papers presented in this SI show cutting edge research on how atmospheric pollutants change our environment focusing on air quality, global warming, and the impacts on health. Authors and reviewers are greatly acknowledged for their contributions as well as Dr. Philippe Garrigues, ESPR Editor-in-Chief, and Emmanuelle Pignard-Péguet and Laure Beugnot, Editorial Assistants, for their help and support during the preparation of this special issue. For additional information about the E2KW 2013 conference speakers and titles, please visit http://congresse2kw.uclm.es/e2kw-2013. This conference is organized by the Energy and Environment Science and Technology Campus of International Excellence-CYTEMA of the University of Castilla-La Mancha (Spain).

\section{References}

Ballesteros, B., Ceacero-Vega, A.A., Jiménez, E., Albaladejo, J., (2015) Atmospheric reactions of methylcyclohexanes with $\mathrm{Cl}$ atoms and $\mathrm{OH}$ radicals: determination of rate coefficients and degradation products. Environ Sci Pollut Res, doi: 10.1007/s11356-014-2901-0

Balsalobre D, Álvarez-Herranz A, Cantos Cantos JM (2015) Public budgets for energy RD\&D and the effects on energy intensity and pollution levels. Environ Sci Pollut Res. doi:10.1007/s11356-0143121-3

Da G, Géhin E, Ben-Othmane M, Havet M, Solliec C, Motzkus C (2015) An experimental approach to measure particle deposition in large circular ventilation ducts. Environ Sci Pollut Res. doi:10.1007/ s11356-014-2859-y

Dadi T, Rubio Caballero EM, Martínez García E, López Serrano FR, Andrés Abellán M, García Morote FA, De las Heras Ibáñez JA (2015) Post-wildfire effects on carbon and water dynamics in a Spanish black pine forest. Environ Sci Pollut Res. doi:10.1007/ s11356-014-3744-4

Environmental Protection Agency. http://www.epa.gov/ groundlevelozone/health.html

Esbrí JM, López-Berdonces MA, Fernández-Calderón S, Higueras P, Diez S (2015) Atmospheric Mercury Pollution around a ChlorAlkali Plant: an Integrated Analysis. Environ Sci Pollut Res. doi: 10.1007/s11356-014-3305-x

European Environment Agency (2013) Assessment on heavy metal (HM) emissions (APE 005)

García-Gómez M, Caballero-Klink JD, Boffetta P, Español S, Sällsten G, Gómez-Quintana $J$ (2007) Exposure to mercury in the mine of Almadén. Occup Environ Med 64(6):389-395

González, S., Jiménez, E., Ballesteros, B., Martínez, E., Albaladejo, J. (2015) Hydroxyl radical reaction rate coefficients as a function of temperature and IR absorption cross sections for $\mathrm{CF}_{3} \mathrm{CH}=\mathrm{CH}_{2}$ (HFO-1243zf), Potential Replacement of $\mathrm{CF}_{3} \mathrm{CH}_{2} \mathrm{~F}$ (HFC-134a) Environmental Science and Pollution Research, doi: 10.1007/ s11356-014-3426-2.

Ifang, S., Barnes, I., Benter, T., (2015) Reactions of Cl Atoms with alkyl esters: kinetic, mechanism and atmospheric implications. Environ Sci Pollut Res, doi: 10.1007/s11356-014-2913-9

Janssen NAH, Gerlofs-Nijland ME, Lanki, T, Salonen RO, Cassee F, Hoek G, Fischer P, Brunekreef B, Krzyzanowski M (2012) World Health Organization-Regional for Europe Health effects of black carbon

Ravishankara AR (1997) Heterogeneous and multiphase chemistry in the troposphere. Science 276:1058-1065

Tapia A, Salgado S, Martín P, Sanchez-Valdepeñas J, Rossi MJ, Cabañas B (2015) The use of heterogeneous chemistry for the characterization of functional groups at the gas/particle interface of soot from a diesel engine at a particular running condition. Environ Sci Pollut Res. doi:10.1007/s11356-014-2976-7

Tejero J, Higueras PL, Garrido I, Esbrí JM, Oyarzun R, Español S (2015) An estimation of mercury concentrations in the atmosphere of Almadén (Ciudad Real Province, South-Central Spain) during the $20^{\text {th }}$ century. Environ Sci Pollut Res. doi:10.1007/s11356-014$2860-5$ 


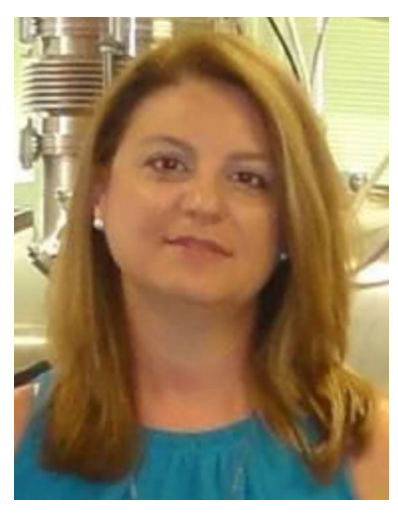

Elena Jiménez is Associate Professor in the Physical Chemistry Department at the University of Castilla-La Mancha (Ciudad Real, Spain). She got the $\mathrm{PhD}$ degree in Chemistry from UCLM in 2001 under the supervision of Prof. Ernesto Martínez Ataz and Prof. José Albaladejo Pérez. She was the vice-Head of the Department of Physical Chemistry from 2009 to 2012 . Her educational and research career started in 1995, teaching at undergraduate and post-graduate levels. Her research has been focused on the atmospheric chemistry and photochemistry of oxygenated organic compounds. Currently, a new research line related to the chemistry of the interstellar medium has been started and awarded with a Synergy grant (together with several Spanish and French research groups) from the European Research Council in the 7th Research Framework Program. From 2002 to 2003, she worked as a Research Associate at the National Oceanic and Atmospheric Administration (NOAA) at Boulder (Colorado, USA) under the supervision of Prof. A. R. Ravishankara, co-chair of the WMO/UNEP Science Assessment Panel on Stratospheric Ozone. She has been a visiting professor at the University of Lille 1 (France) and a visiting scientist at NOAA and the French CNRS at Orléans. Since 2009 is an active member of the Environmental Science and Technology (ES\&T) editorial advisory board (EAB) and in 2013 she became an EAB member of a new journal, Current Environmental Engineering. Her research has been published in international journals such as ES\&T, Atmospheric Chemistry and Physics, Journal of Physical Chemistry A, Atmospheric Environment, Chemical Physics Letters, Physical Chemistry Chemical Physics and ChemPhysChem.

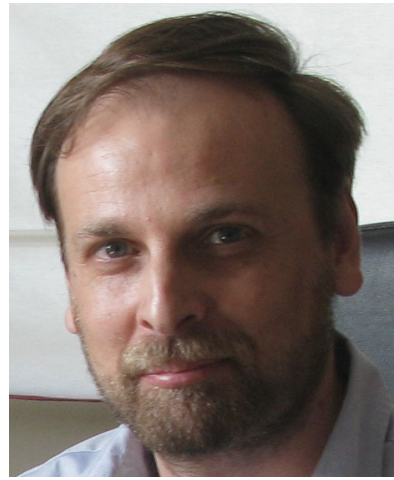

Francisco J. Tapiador is the Dean of the Faculty of Environmental Sciences and Biochemistry at UCLM (Universidad de Castilla-La Mancha, Toledo, Spain). He graduated in and received a master degree (Licenciatura) in Geography (inc. Erasmus at University College Cork, Ireland) and a PhD in Physics at the University of Valladolid (Spain). As a postdoc, he spent three years at the University of Birmingham (UK), working in precipitation science. He came back to Spain in 2004, hired by the Ramon y Cajal program. After this period, he was recognized as Outstanding Career Scientist in 2009 (I3 program). He has been a visiting scholar at the Universities of Paris (France), Cambridge (UK), Oklahoma/National Weather Center (USA), Colorado State University (USA), and the Jet Propulsion Laboratory (JPL, Caltech/NASA, USA). He has published his research in journals such as the International Journal of Remote Sensing, Energy and Environmental Sciences, Cellular Polymers, Physical Chemistry Chemical Physics, Bulletin of the American Meteorological Society, Journal of Climate, Journal of Hydrometeorology, Journal of Applied Meteorology, Tellus, Meteorological Applications, Atmospheric Research and Geophysical Research Letters. He is on the science team of NASA/JAXA GPM Mission.

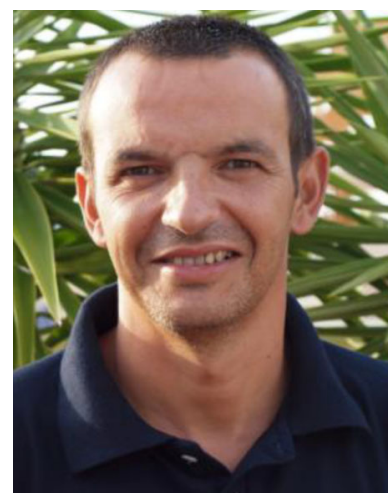

Francisco José Sáez-Martínez is Associate Professor of General Management at the Faculty of Economics, University of Castilla-La Mancha (UCLM), Spain. He received a degree in Economics and Business Administration from the University of Valencia (incl. Erasmus at Cardiff Business School, Wales University, UK) and a PhD in Management from the University of Castilla-La Mancha. Since July 2012 he is Coordinator of CYTEMA the Energy and Environment Science and Technology Campus of International Excellence. He has recently been appointed member of the technical and consulting scientific committee of the Spanish National Hydrogen Centre - $\mathrm{CNH} 2$ - and has been visiting researcher at Purdue University (USA) and Dublin City University (Ireland) and visiting lecturer at Universidad del Pacífico (Perú), Universidad Andina Simón Bolívar (Bolivia) and Universidad Autónoma Gabriel René Moreno (Bolivia). His research has been published in international journals such as Journal of Business Ethics; Journal of Knowledge Management; Journal of Corporate Governance; Innovation: Management, Policy and Practice; International Journal of Services Technology and Management; Environmental Engineering and Management Journal; and International Journal of Environmental Research. His current research interest is focused on corporate entrepreneurship and eco-innovation. 